\title{
Basal Cell Adenoma of the Submandibular Gland
}

\author{
M. Veeresh • Radhika M. Bavle $\cdot$ Kashi N. Vinay • \\ H. Nandakumar
}

Received: 2 February 2010/ Accepted: 3 July 2010/Published online: 17 October 2010

(C) Association of Oral and Maxillofacial Surgeons of India 2010

\begin{abstract}
Basel cell adenoma is a benign epithelial salivary gland tumor that appears to have unique histologic characteristics. The diagnosis of this entity must be established by histological study. It commonly occurs in parotid gland and very rarely in submandibular gland. Here we report a case of basel cell adenoma of submandibular gland.
\end{abstract}

Keywords Basal cells · Submandibular gland · Adenoma

\section{Introduction}

Salivary gland tumors constitute about $3-4 \%$ of all head and neck neoplasm. Approximately $80 \%$ originate in the parotid gland [1] and they are rarely present in the submandibular gland.

Basal cell adenoma is a benign epithelial salivary gland tumor that appears to have unique histologic characteristics.

It was included as a separate salivary gland tumor in the classification schemes by WHO in 1991 [2] the incidence of basal cell adenoma is $1-2 \%$ of all salivary gland tumors. The most common site for a basal cell adenoma is parotid gland with $73.1 \%$ incidence in this location [2] and seen in

M. Veeresh $(\bowtie) \cdot$ K. N. Vinay $\cdot H$. Nandakumar

Department of Oral and Maxillofacial Surgery, Krishnadevaraya

College of Dental Sciences, Bangalore, India

e-mail: drveeresh1976@rediffmail.com

R. M. Bavle

Department of Oral and Maxillofacial Pathology,

Krishnadevaraya College of Dental Sciences, Bangalore, India

M. Veeresh

Department of Oral and Maxillofacial Surgery, Bangalore

Institute of Oncology, Bangalore, India
$20 \%$ of salivary glands especially in upper lip. The majority of occurrence is seen in patients of 60 years or older [3]. It usually appears as a firm and mobile slowgrowing mass [5].

We report here a case of a middle aged woman with basal cell adenoma of submandibular gland. The clinical presentation, pathological features, differential diagnosis and treatment options for this relatively rare tumor are discussed.

\section{Case Report}

A 65 year old woman reported to our hospital with a complaint of painless mass in her right submandibular region since 1 year, which was measuring nearly $2.5 \times 3 \mathrm{~cm}$. Initially it was small which progressed to the present size (Fig. 1).

The swelling was moderately firm. A conventional orthopantomogram revealed no bone destruction. Fine needle aspiration cytology (FNAC) was performed, which revealed low cytological grade epithelial proliferation. This finding was comparable with pleomorphic adenoma.

The surgical excision of the mass was done under general anesthesia. Hemostasis was achieved and the wound was closed in two layers (Figs. 2, 3, 4).

Follow up is done for 2 years and there is no sign of recurrence. The excised mass was sent for histopathological examination. The report suggested basal cell adenoma of submandibular gland. The section showed numerous small nests of epithelial cells having basaloid morphology. The basaloid cells are also arranged in the form of interlacing chords and strands merging with each other. The cells appear uniform, without mitosis. The peripheral collagen bands form a capsular structure around the proliferating epithelial cells (Fig. 5). 


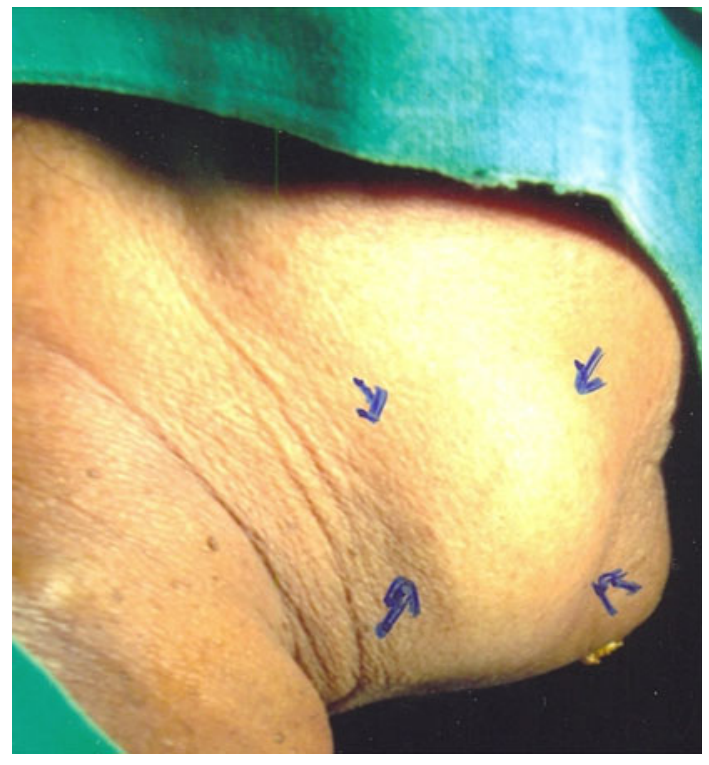

Fig. 1 Pre operative picture

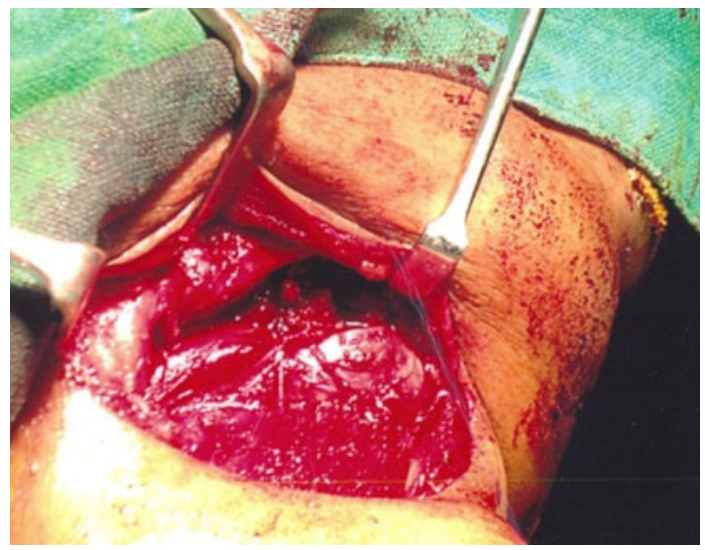

Fig. 2 After excision of the lesion

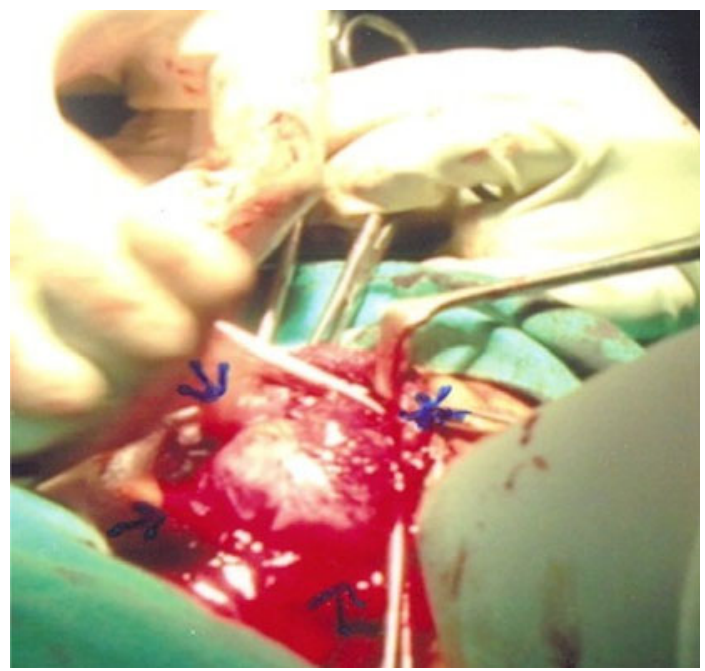

Fig. 3 Lesion exposed

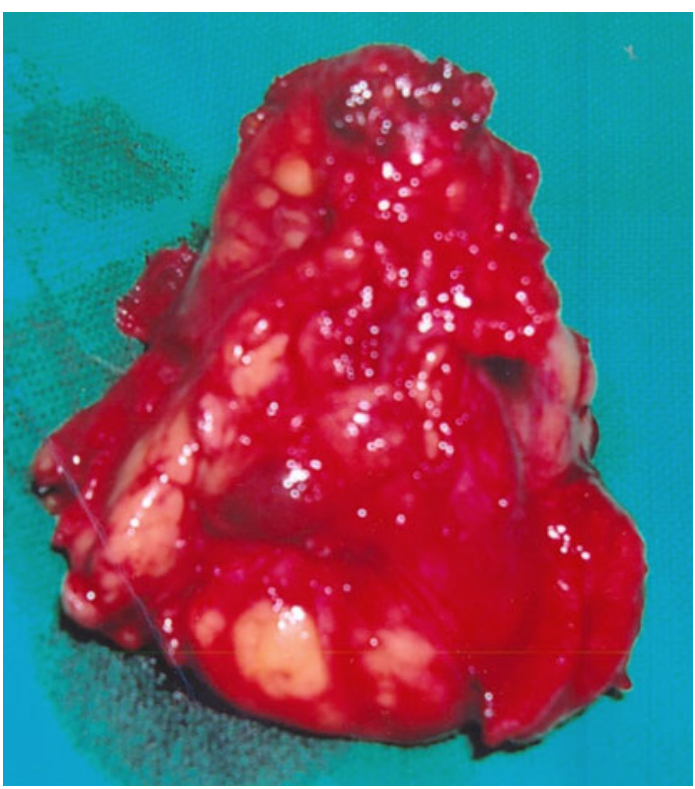

Fig. 4 Excised lesion

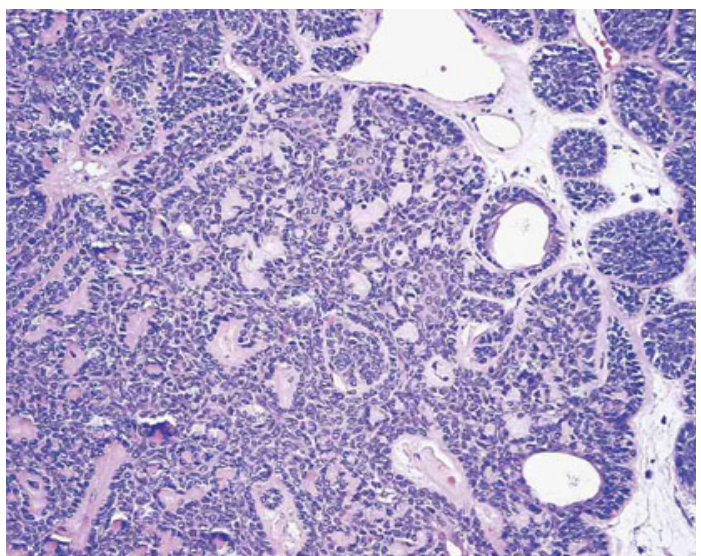

Fig. 5 Histopathologic picture

\section{Discussion}

The basal cell adenoma was first reported as a distinct entity by Kleinsasser and Klein in 1967. Batsakis is credited with reporting the first case in the American literature in 1972 and suggested that the intercalated duct or reserve cell is the histogenic source of basal cell adenoma.

Basal cell adenoma, as defined by WHO, is a distinctive benign neoplasm composed of basaloid cells organized with a prominent basal cell layer and distinct basement membrane-like structure and no myxochondroid stromal component as seen in pleomorphic adenomas. Three cellular patterns occur: solid, trabecular-tubular, and membranous. The common clinical feature of basal cell adenoma is a slow-growing, asymptomatic, freely movable parotid mass, which is often observed in women above 50 years of age [4]. 
Adenoma is a benign epithelial tumor in which the cells from recognisable granular structures or in which the cells are derived from glandular epithelium [3]. Basal cell adenoma is a specific type of monomorphic tumor of the salivary glands that closely resembles basal cell lesions of the skin. Solid BCA are formed by small cells organized in a compact manner. In the trabecular and tubular subtypes, important groups of cells exist. They are disposed in narrow bands and ductal structures or in a combination of both. Membranous subtype is constituted by external cells in a stockade pattern and by an intense hyalinised basal membrane.

The diagnosis of this entity must be established by the histological study. Generally biopsy is accepted as the most accurate method to obtain diagnosis, although some authors advocate FNAC if physical access to the tumor is available [5].

Histologically, BCA is characterized by the presence of uniform and regular basaloid cells. These cells have two differenced morphologies and are intermingled. One group consists in small cells with little cytoplasm and intensive basaloid rounded nuclei that are usually located in the periphery of the tumoral nests or islands. The other group is formed by large cells with abundant cytoplasm and pale nuclei that are located in the centre of the tumoral nests. A basal membrane-like structure rounds these tumoral nests, separating them from the surrounding connective tissue. Globally, as it has been referred in classic texts, the tumor adopts an ameloblastoma-like pattern.

Differential diagnosis must be established with some unfavourable entities such as basal cell adenocarcinoma, adenoid cystic carcinoma, basaloid squamous cell carcinoma.

In contrast to basal cell adenoma, an infiltrative growth, more mitotic figures and KI67 staining of 5\% of the cells are observed in basal cell carcinoma.

In adenoid cystic carcinoma, which pool of epithelial cells, dark external cells in a stockade pattern and a thick basal membrane-like structures are observed. Tumor nests are clearly differentiated from inter epithelial stroma because of an intact basal cell membrane. This delimitation is observed neither in the pleomorphic adenoma nor in the adenoid cystic carcinoma [5].

The imaging features of this pathological entity are not well described [6].
Basal cell adenomas are amenable to conservative resection such as local excision or superficial removal of the gland, whereas the membranous subtype requires complete resection of the entire gland. The recurrence rate for the solid and trabecular-tubular variants is almost nonexistent. This contrasts with the high recurrence rate (24\%) of the membranous type, which is perhaps a result of the multicentricity of this lesion. Although exceedingly rare, malignant transformation is more common in the membranous type than in the other types [4].

\section{Conclusion}

Basal cell adenoma is a specific type of monomorphic tumor of salivary glands that closely resembles basal cell lesions of the skin. And also it is necessary to perform a complete excision of the tumor prior to the making of the final diagnosis.

Due to prognostic implications, differential diagnosis with basal cell adenocarcinoma, adenoid cystic carcinoma, and basaloid squamous cell carcinoma is mandatory.

\section{References}

1. Lin H-C, Chien C-Y, Huang S-C, Su C-Y (2003) Basal cell adenoma of the sublingual gland. Ann Otol Rhinol Laryngol 112(12):1066-1068

2. Hiranuma T, Kagamiuch H, Kitamura R (2003) A basal cell adenoma of the sublingual gland. Int $\mathrm{J}$ Oral Maxillofac Surg 32:566-567

3. Canalis RF, Mok MW, Fishman SM, Hemenway WG (1980) Congenital basal cell adenoma of the submandibular gland. Arch Otolaryngol Head Neck Surg 106(5):284-286

4. Jang M, Park D, Lee SR, Hahm CK, Kim Y, Kim Y, Park CK, Tae K, Park MH, Park YW (2004) Basal cell adenoma in the parotid gland: CT and MR findings. AJNR Am J Neuroradiol 25:631-635

5. Gonzalez-Garcia R, Nam-Cha SH, Munoz-Guerra MF, GamalloAmat C (2006) Basal cell adenoma of the parotid gland. Case report and review of the literature. Med Oral Patol Oral Cir Bucal 11:E206-E209

6. Chawla AJ, Tan TY, Tan GJS (2006) Basal cell adenomas of the parotid gland: CT scan features. J Vasc Interv Radiol 58(2):260-265 